\title{
Prevalence of asymptomatic visceral leishmaniasis in human and dog, Benishangul Gumuz regional state, Western Ethiopia
}

\author{
Shibabaw Bejano 1,2,3, Girma Shumie ${ }^{1}$, Ashwani Kumar ${ }^{3}$, Eyuel Asemahagn ${ }^{1}$, Demekech Damte , \\ Sinkinesh Woldie ${ }^{1}$, Abate Mulugeta ${ }^{4}$, Nigus Manaye ${ }^{5}$, Abebe Genetu ${ }^{1}$, Endalamaw Gadisa ${ }^{{ }^{*+}+(\mathbb{D}}$ \\ and Gezahegn Mamo ${ }^{3+}$
}

\begin{abstract}
Background: The Benishangul-Gumuz region is an important development corridor in Ethiopia. Large-scale projects such as the Great Renaissance Dam, mining and agriculture have entailed huge environmental modifications and settlement pattern changes. There is no detailed epidemiological information on visceral leishmaniasis $(\mathrm{VL})$ in the region.

Materials and methods: A cross-sectional study was carried out to assess the epidemiology and risk factors associated with Leishmania infection. A leishmanin skin test (LST) was done for 1342 participants, and for 253 of them rK39 and DAT were carried out. Thirty-six dogs owned by households with LST-positive member(s) were rK39 and DAT tested. A pretested questionnaire was used to capture individual and household characteristics.

Results: Of the $89.2 \%$ (1197/1342) who availed themselves of the LST reading, $6.0 \%$ were positive. The rk39 and DAT positivity among the 253 tested were $3.2 \%$ and $5.9 \%$, respectively. In dogs, positivity rates by rK39 and DAT were $13.9 \%$ and $5.6 \%$, respectively. Of the household and individual risk factors, presence of a dog in the household $(P=0.005)$, male sex (0.003), residence woreda $(0.000)$ and occupation $(0.023)$ showed a strong positive association with LST positivity. Individuals who lived in households that had dogs were 2.6 times more likely to be LST positive $(A O R=2.6 ; 95 \% \mathrm{Cl}=1.54,4.40)$. Being female decreased the probability of being LST positive by 0.38 times $(A O R=0.38 ; 95 \% \mathrm{Cl}=0.20,0.72)$. People living in Guba and Kurmuk had $4.7(\mathrm{AOR}=4.74,95 \% \mathrm{Cl} 1.83,12.31)$ and 5.9 $(\mathrm{AOR}=5.85,95 \% \mathrm{Cl} 2.27,15.09)$ times more risk of being infected.
\end{abstract}

Conclusions: We demonstrated the presence of active $V L$ transmission in the areas. Thus, we underline the need to establish the responsible vector(s) and reservoir(s) for comprehensive early containment plans to prevent potentially harmful public health and economic consequences.

Keywords: Benishangul Gumuz, Direct agglutination test, Dog, Human, Leishmanin skin test, rK39-ICT, Visceral leishmaniasis

*Correspondence: endalamaw.gadisa@ahri.gov.et

†Endalamaw Gadisa and Gezahegn Mamo contributed equally to this work

${ }^{1}$ Armauer Hansen Research Institute, Neglected Tropical Disease and Malaria Research Directorate, Addis Ababa, Ethiopia

Full list of author information is available at the end of the article

\section{Background}

Visceral leishmaniasis (VL, Kala-azar) is a neglected tropical disease that can be fatal without early diagnosis and proper treatment. VL in east Africa is caused by the Leishmania donovani species complex. The transmission of $L$. donovani is generally considered anthroponomic. Jambulingam et al. [1] provided definitive evidence incriminating

c) The Author(s) 2021. This article is licensed under a Creative Commons Attribution 4.0 International License, which permits use, sharing, adaptation, distribution and reproduction in any medium or format, as long as you give appropriate credit to the original author(s) and the source, provide a link to the Creative Commons licence, and indicate if changes were made. The images or other third party material in this article are included in the article's Creative Commons licence, unless indicated otherwise in a credit line to the material. If material is not included in the article's Creative Commons licence and your intended use is not permitted by statutory regulation or exceeds the permitted use, you will need to obtain permission directly from the copyright holder. To view a copy of this licence, visit http://creativeco mmons.org/licenses/by/4.0/. The Creative Commons Public Domain Dedication waiver (http://creativecommons.org/publicdomain/ zero/1.0/) applies to the data made available in this article, unless otherwise stated in a credit line to the data. 
dogs as a $L$. donovani reservoir in India, but the status in east Africa remains to be substantiated. However, there are reports that associated dogs with $L$. donovani transmission in the Sudan [2,3] and Ethiopia [4-6]. Also, studies have shown that dogs are among the domestic animals that $P$. orientalis, the vector of $L$. donovani in east northern Ethiopia foci, preferentially bites $[7,8]$.

Visceral leishmaniasis (VL) is reemerging with geographic spread and recurrent outbreaks that have claimed the lives of several hundred Ethiopians over the past 2 decades [9]. Among the factors contributing to its spread and outbreaks are individual, household and socio-geographic risk factors: age, sex, housing conditions, mass movement of temporary laborers, immunosuppression and ecological modifications [9-12]. The national incidence estimate for Ethiopia based on self-reported cases is up to 4500 new cases per year [13]. The risk model using the geographical information system and statistics showed that about $33 \%$ of the total landmass, predominantly within development corridors with significant public health and economic implications, is at high risk for VL [14].

Benishangul-Gumuz regional state is one of the fastest changing development corridors in western Ethiopia. Mega-projects, such as the Great Ethiopian Renaissance Dam, large-scale irrigation and rain-fed commercial agriculture areas and mining activities, have resulted in vast ecological and sociodemographic changes. The rapid assessment by Abera et al. [15] reported a 7.3\% (20/275) $\mathrm{VL}$ asymptomatic infection prevalence in two kebeles (sub-districts) where a VL patient was reported to have lived [16].

Control strategies for leishmaniasis in Ethiopia rely on case detection and treatment and on vector control. Thus, delineating endemic areas and knowledge about the burden help to attain desired outcomes by targeting resources. Also, knowledge on risk factors associated with exposure is important to design behavioral change communication tools to attain active participation and ownership of programs by affected communities. Therefore, the objective of this study was to assess the epidemiology and risk factors associated with leishmaniasis in humans and dogs in high-risk districts.

\section{Materials and methods}

\section{Description of study area}

The location of the Benishangul-Gumuz region, western Ethiopia, is $34^{\circ} 10^{\prime} \mathrm{N}, 37^{\circ} 40^{\prime} \mathrm{E}$ and $09^{\circ} 17^{\prime} \mathrm{N}, 12^{\circ} 06^{\prime} \mathrm{N}$. The region is predominantly (75\%) lowlands. The total population is around 784,345 with an estimated density of 15.91 people per square kilometer (BGRoHB 2019). The study encompassed six areas at high risk of VL (Fig. 1) as per the environmental factor-based risk model by Tsegaw et al. [14]: Dangur, Guba and Pawi from the Metekel Zone and Banbasi, Kumruk and Sherkole from the Assosa Zone. The region is one of the development corridors with large-scale agricultural, mining and dam projects, which have changed the settlement pattern and caused deforestations and a large influx of people for temporary work and/or permanent settlement.

\section{Study design and sample size determination}

A cross-sectional survey was done from 2018 to 2020 to assess the epidemiology and explore whether there was any zoonotic significance of VL and risk factors associated with exposure to Leishmania infection. Samples were selected using a multi-staged sampling technique. As the primary sampling unit among the three administrative zones of the region, overlaying the environmental factor-based risk map [14], two zones, namely Assosa and Metekel, were selected because they had large areas at high risk of VL. Similarly, within the selected zones, districts with high-risk areas were selected. Then, an operation map was prepared overlaying the risk map of selected districts and the kebele level shapefile to identify high-risk kebeles. Subsequently, study households were randomly selected from each of the kebeles targeting up to $5 \%$ of their total population, with overall sample size of 1342 individuals for LST testing.

Following LST-reactive individuals as a focal point, dogs were sampled for serological tests, rK39 and DAT. Also, 253 human blood samples, 67 purposively from LST-reactive and 185 randomly from non-reactive individuals, were tested by DAT and rK39.

After explaining the purpose of the study, a written informed consent form was obtained from each participant or the parents or guardians for minors. Similarly, informed assent was obtained from dog owners to sample dogs. Blood sample were aseptically collected using 5 -ml disposable syringes or plain vacutainer tubes from cephalic/saphenous veins of both humans and dogs. Of the collected blood, $20 \mu \mathrm{l}$ was used to prepare dried blood spots (DBS) on 3MM Whatman paper (Whatman, Maidstone, UK) allowed to fully air dry without exposing to direct sunlight. Sera from both dog and human were used for rK39 ICT and DAT testing.

\section{Leishmanin skin test (LST)}

Prior to LST, socio-demographic information was documented from the study participants using a pre-tested semi-structured questionnaire. Then, an intradermal injection of $0.1 \mathrm{ml}$ leishmanin antigen (Pasteur Institute of Iran, Tehran, prepared from L. major) was made at the volar surface of the arm. After 48-72 h, the delayed hypersensitivity reaction was measured with the ballpoint techniques; $5.0 \mathrm{~mm}$ and above of the average of 
the two diameters of an induration was considered positive (Fig. 2).

\section{rk-39 immunochromatographic test (rK39 ICT)}

The rK39 ICT (DiaMed- ITLEISH; Bio-Rad Laboratories, Marnes-la-Coquette, France) was done following the supplier's recommendations. In brief, a 20- $\mu \mathrm{l}$ serum sample was added to the absorbent pad well with $150 \mu \mathrm{l}$ (2-3 drops) of the chase buffer provided with the kit. Results were read after 10-20 min and recorded as follows: positive when both control and test lines appeared; negative when only control line appeared or invalid when no control line appeared (in such cases tests were repeated) (Fig. 3).

\section{Direct Agglutination Test (DAT)}

Sera were transported to Benishangul Gumuz Regional Laboratory in an ice box and stored at $-20{ }^{\circ} \mathrm{C}$. Then, samples were transported to AHRI under cold chain and stored at $-20{ }^{\circ} \mathrm{C}$ until processed. A direct agglutination test was performed according to the manufacturer's instructions (Institute of Tropical Medicine, Antwerp, Belgium). The presence of antileishmanial antibodies below or at cutoff of 1:3200 titers was used to determine negativity. Both negative and positive controls were run for every batch of kit used. In brief, sera were diluted serially from $1: 200$ to $1: 204800$ by transferring $50 \mu \mathrm{l}$ of diluted serum and discarding the same amount from the last dilution (Fig 4).

\section{Data analysis}

STATA version 13 data software (College Station, TX, USA) was used for data analysis. Descriptive statistics were employed to summarize in terms of frequencies and percentages. Univariate and multivariate logistic regressions were used to determine the association of Leishmania infection with the risk factors and expressed as odds ratio and 95\% confidence interval.

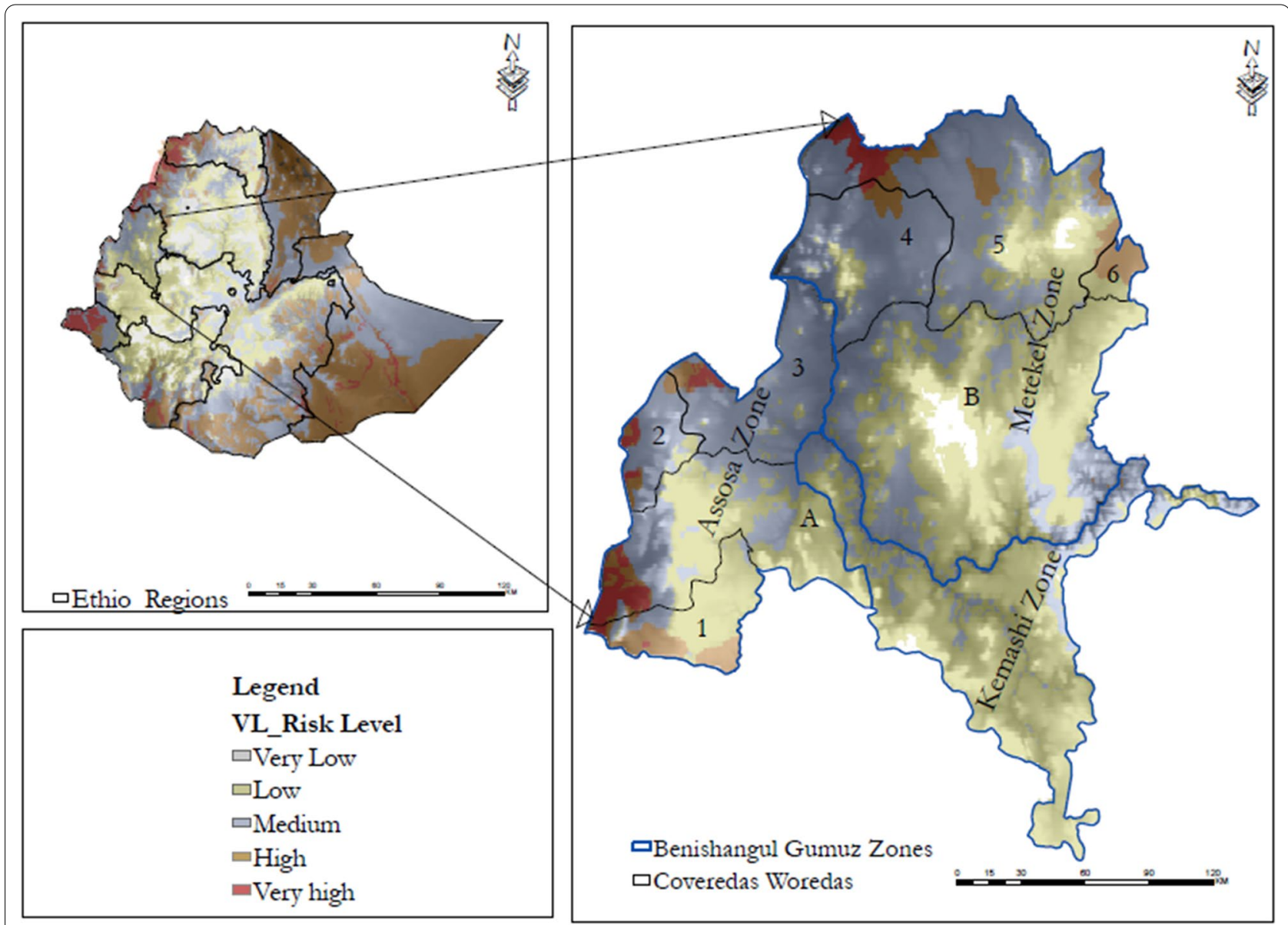

Fig. 1 Map of the study woredas: $1=$ Bambasi, $2=$ Kurmuk and 3=Sherkole from the Assosa Zone; $4=$ Guba, $5=$ Dangur and $6=$ Pawi from the Metekel Zone, Benishangul Gumuz regional state, Western Ethiopia 
For all analyses, $P<0.05$ was considered a significant difference.

\section{Ethical considerations}

The protocol was approved by the AHRI/ALERT ethical review committee (AH01275/0012/18, 19/12/18). Informed consent was obtained from all participants or guardians/parents of minors. For participants between 11 and 18 years, verbal assent was sought in addition to the parental/guardian consent. Similarly, for dogs informed consent was obtained from the owners.

\section{Result}

\section{Prevalence of asymptomatic visceral leishmaniasis}

Of the total 1342 participants LST tested, 89.2\% (801 males and 396 females) were available for result reading. The LST-based prevalence was $6.0 \%$ (72/1197). The seroprevalence was $3.2 \%(8 / 253)$ and $5.9 \%(15 / 253)$, respectively, by rk39 and DAT. Three of the 8 rk39 and 7 of the 15 DAT-reactive individuals were LST positive, while 5 of the rk39 and 8 of those DAT reactive were LST negative (Table 1).

Variation in asymptomatic infection was observed among sites: higher prevalence was detected in kebeles from Guba $(16.1 \%, 32 / 199)$ and Kurumuk (14.0 \%, 27/191) districts, respectively. The highest LST positivity was recorded at Abulhorse kebele $(28.3 \%, 17 / 60)$ from Guba district (Table 2).

\section{Seroprevalence of asymptomatic visceral leishmaniasis in dogs}

Of the 36 dogs owned by households that had LSTreactive member(s), $5(13.9 \%)$ and $2(5.6 \%)$ were reactive according to rk39 and DAT, respectively (Table 3 ). The trend in distribution of the seroprevalence in dogs paralleled that observed in humans; more positive dogs were found in sites where there were more LST-positive humans (Tables 2 and 3 ).

\section{Factors associated with asymptomatic Leishmania infection}

Exposure to Leishmania infection showed a significant gender difference. Females were about 0.4 times less likely to be affected compared to males $(\mathrm{AOR}=0.38$; $95 \%$ CI $0.20,0.72$ ). Yet age showed no significant association with VL exposure. Presence of a dog in a household was found to increase the likelihood of being LST positive by 2.6 -fold ( $\mathrm{AOR}=2.60 ; 95 \% \mathrm{CI} 1.54,4.40)$. Living in Kurmuk district (AOR 5.85, 95\% CI 2.27, 15.09) had the highest risk followed by Guba district (AOR 4.74, 95\% CI $1.83,12.31$ ) (Table 4).

\section{Discussion}

Benishangul-Gumuz is one of the crucial development corridors in western Ethiopia. Accompanying the largescale projects are huge sociodemographic and ecological changes. Large areas in the region were predicted to have a high VL risk based on the environmental factor-based geographical information and statics risk mapping [14]. However, data hardly exist on the epidemiology of VL in the region [15]. To our knowledge, this epidemiological survey is the first to assess the asymptomatic Leishmania infection rate covering wider high-risk districts in the regions with humans and dogs.

The prevalence of Leishmania infection was $6.0 \%$ based on LST positivity. The seroprevalence in human Leishmania infection was $3.2 \%(8 / 252)$ by rk39 and $5.9 \%(15 / 252)$ by DAT. The LST positivity rate of $5.4 \%$ in our study is in agreement with the previously reported Leishmania

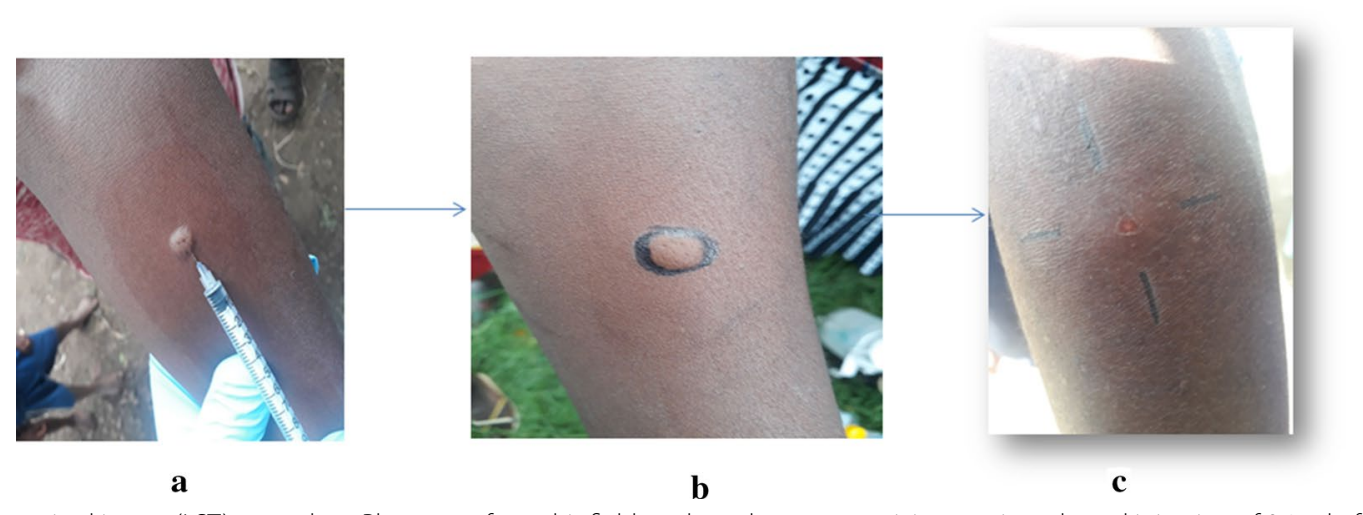

Fig. 2 Leishmanin skin test (LST) procedure. Photos are from this field work on the same participant: a intradermal injection of $0.1 \mathrm{ml}$ of LST (Pasteur Institute of Iran, Tehran, Iran) solution after brief shaking. b Marking of the injection point using permanent marker and $\mathbf{c}$ measuring the induration using the ballpoint pen method after 48 to $72 \mathrm{~h}$ of injection 


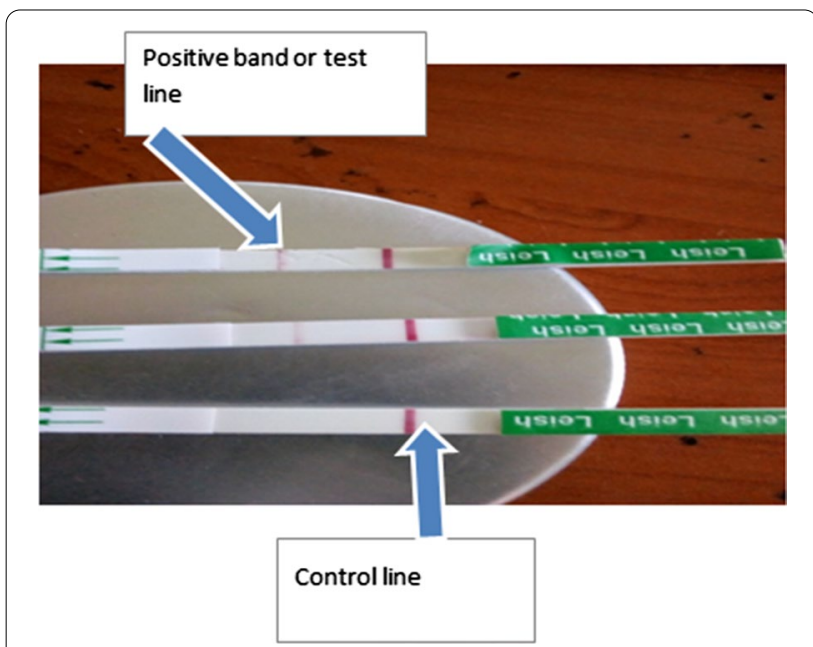

Fig. 3 rK39 immunochromatographic test interpretation: top two: positive strips: bottom: negative strip

infection prevalence reported by Hailu et al. [4] from Aba Roba, southern Ethiopia, and Bsrat et al. [17] from Welkait, northern Ethiopia, of $5.6 \%$ and $5.88 \%$, respectively. It is lower than the results reported by Ali et al. [19] from the lower Awash valley, eastern Ethiopia, and Tadese et al. [20] from Raya Azebo, northeastern Ethiopia, who reported reactive rates of $38.3 \%$ and $9.08 \%$, respectively. The seroprevalence in Benishangul-Gumuz according to rK39 (3.2\%) was lower than that in the report by Alebie et al. [21] from the Gode and Adale districts of the Shebele Zone (12.7\%), southeastern Ethiopia. The DAT positivity rate was in agreement with that of Hailu et al. [18], who found 5.4\%, and higher than that of Tadese et al. [19], who reported $0.8 \%$. The difference in prevalence is expected as the risk factors or level of risk factors for exposure to sand fly bites differ in different atrisk communities.

Understanding the determinants of VL exposure in an area is important information for designing infection prevention methods. Thus, we examined personal and household factors connected with $L$. donovani infections. The significant differences in exposure between males and females observed in the present study were supported by Ali et al. [20], Hailu et al. [18] and Bantie et al. [20]. This could be because males are mostly engaged in outdoor activities and stay outdoors, which might increase their chances to have sand fly bites.

In the current study participants who owned dogs had a 2.6 (95\% CI 1.54, 4.40) times higher chance of being LST positive, a finding that paralleled the report by Bsrat et al. [4], but the seroprevalence in dogs was higher in the current study. This difference might because we purposely sampled dogs owned by households with LST-positive members and also the small sample size, as our aim was

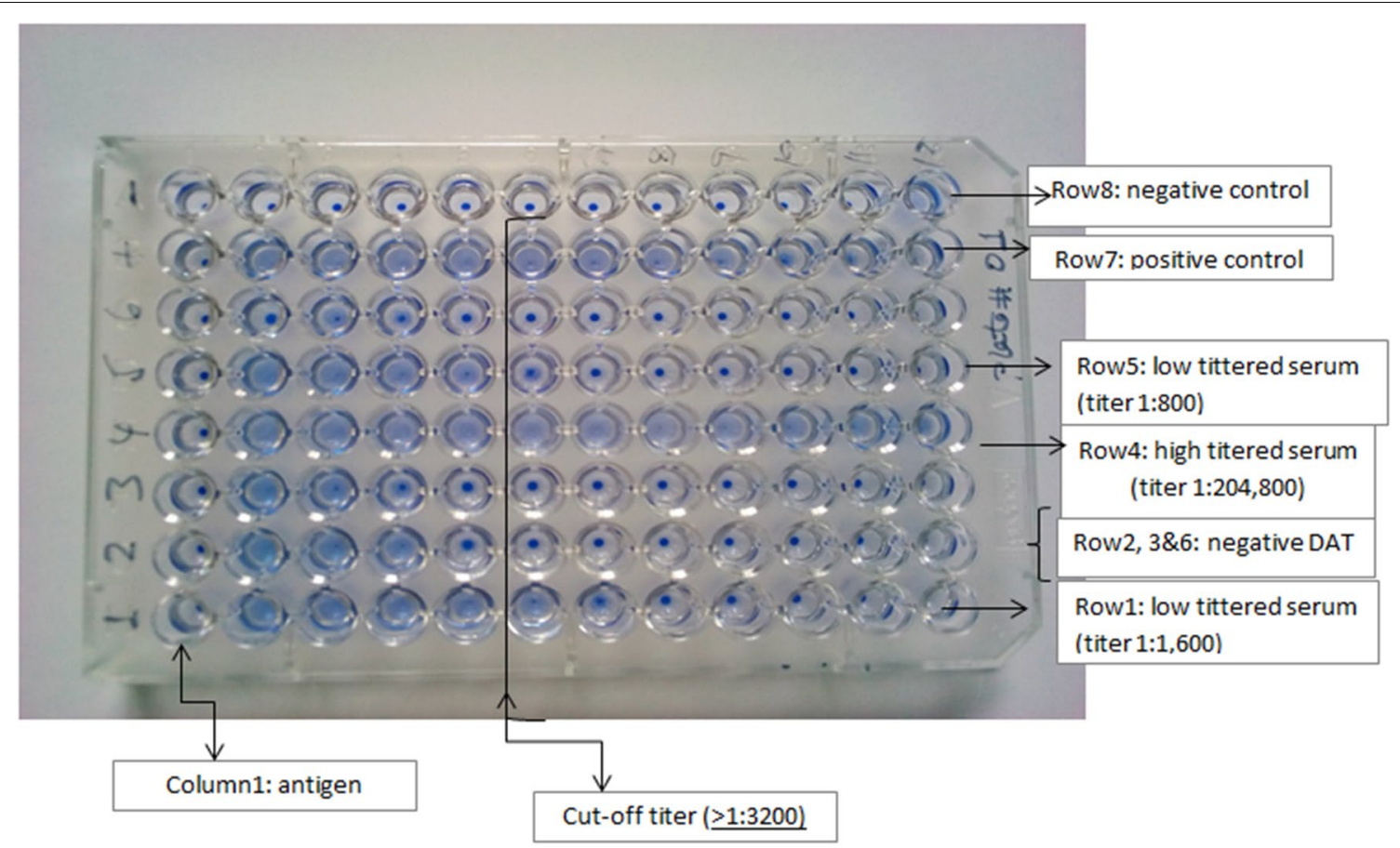

Fig. 4 A plate showing the DAT test results in sera tested with a starting dilution of 1:200 in column 
Table 1 Prevalence of asymptomatic visceral leishmaniasis in Benishangul Gumuz, western Ethiopia, by age and sex as measured by LST ( $n=$ tested positive, $N=1197)$, DAT ( $n=$ tested positive, $N=253)$ and rK39 ( $n=$ tested positive, $N=253), 2018-2020$

\begin{tabular}{llll}
\hline Variable & LST positive\% $(n / N)$ & rK39 positive\% $(n / N)$ & DAT positive\% $(n / N)$ \\
\hline Sex & & & $5.81(10 / 172)$ \\
$\quad$ Male & $7.37(59 / 801)$ & $3.49(6 / 172)$ & $6.17(5 / 81)$ \\
$\quad$ Female & $3.28(13 / 396)$ & $2.47(2 / 81)$ & $0(0 / 2)$ \\
Age (in years) group & & & $3.03(1 / 33)$ \\
$<5$ & $0(0 / 2)$ & $0(0 / 2)$ & $6.75(11 / 163)$ \\
$5-12$ & $9.09(3 / 33)$ & $0(0 / 33)$ & $5.45(3 / 55)$ \\
$13-18$ & $30.06(49 / 163)$ & $1.82(1 / 55)$ & \\
$>18$ & $27.27(15 / 55)$ & & $5.163)$ \\
\hline
\end{tabular}

Table 2 Kebele-level asymptomatic visceral leishmaniasis as measured by the leishmanin skin test (LST), Benishangul Gumuz, western Ethiopia

\begin{tabular}{|c|c|c|c|c|}
\hline \multicolumn{3}{|c|}{ Study locations } & \multicolumn{2}{|c|}{ LST reactive $\%(n / N)$} \\
\hline Zone & Woreda & Kebele & Woreda* & Kebele ${ }^{* *}$ \\
\hline \multirow[t]{9}{*}{ Metekel } & Pawi & Mender-104 & $2.73(6 / 220)$ & $0(0 / 71)$ \\
\hline & & Mender-24 & & $8.22(6 / 73)$ \\
\hline & & Hidase & & $0(0 / 76)$ \\
\hline & Guba & Almahal & $16.08(32 / 199)$ & $12.66(10 / 79)$ \\
\hline & & Abulta & & $8.33(5 / 60)$ \\
\hline & & Abulhorse & & $28.33(17 / 60)$ \\
\hline & Dangur & Gubulak & $3.66(7 / 191)$ & $0(0 / 71)$ \\
\hline & & Qota & & $11.67(7 / 60)$ \\
\hline & & Bawulana dilate & & $0(0 / 60)$ \\
\hline \multirow[t]{9}{*}{ Assosa } & Banbasi & Dabus & 0 & $0(0 / 60)$ \\
\hline & & Keshmando & & $0(0 / 70)$ \\
\hline & & Woneba & & $0(0 / 60)$ \\
\hline & Kurumuk & Kurumuk & $14.14(27 / 191)$ & $1.64(1 / 61)$ \\
\hline & & Kutaworke & & $25.00(15 / 60)$ \\
\hline & & Dulshitalu & & $15.71(11 / 70)$ \\
\hline & Sherkole & Mekazen & 0 & $0(0 / 67)$ \\
\hline & & Fadursefabegu & & $0(0 / 68)$ \\
\hline & & Awelbegu & & $0(0 / 71)$ \\
\hline
\end{tabular}

${ }^{*} \operatorname{Pr}=0.000 ;{ }^{* *} \operatorname{Pr}=0.000$

$n=$ number of LST positive and $N=$ number of LST tests per kebele, 2018-2020

not to determine prevalence in dogs but to generate lead data on whether dogs are implicated in the transmission.

The relatively lower Leishmania infection prevalence detected in this study could indicate the probability that $\mathrm{VL}$ is a recent (re)emergence in/introduction to the Benishangul Gumuz region. The lack of significant exposure risk difference between age groups corroborates our argument of VL being a recent phenomenon in the
Table 3 Seropositivity of dogs $(N=36)$ owned by households with LST-positive member(s), Benishangul Gumuz, Western Ethiopia, 2018-2020

\begin{tabular}{|c|c|c|c|c|c|}
\hline \multirow[t]{2}{*}{ Kebeles } & \multicolumn{2}{|l|}{ By rK39 } & \multicolumn{2}{|l|}{ By DAT } & \multirow{2}{*}{$\begin{array}{l}\text { DAT and/or rK39 } \\
\text { Positive } n(\%)\end{array}$} \\
\hline & Tested & Positive & Tested & Positive & \\
\hline Mender-24 & 3 & 0 & 3 & 0 & 0 \\
\hline Almahal & 4 & 1 & 4 & 0 & 0 \\
\hline Abulhorse & 10 & 3 & 10 & 1 & 3 \\
\hline Qota & 4 & 0 & 4 & 0 & 0 \\
\hline Kurumuk & 1 & 0 & 1 & 0 & 1 \\
\hline Kutaworke & 8 & 0 & 8 & 0 & 0 \\
\hline Dulshitalu & 6 & 1 & 6 & 1 & 1 \\
\hline Total & 36 & $5(13.89)$ & 36 & $2(5.56)$ & $5(13.89)$ \\
\hline
\end{tabular}

Benishangul Gumuz Region. Furthermore, there was a relatively higher prevalence in districts such as Guba where high rates of socioecological modifications have taken place within the Benishangul Gumuz and Metekel area, which shares borders with the high VL burdened foci in Amhara. Thus, the recent move to previously uninhabited areas and/or influx of people, mostly project employees (civil servants), from all corners to the region might have precipitated the transmission in the community. Lack of sand fly data and limited purposive sampling of dogs hampered reaching a conclusion as to their contribution to the transmission. The risk factors captured in the study were not exhaustive enough because of the lack of experience with what is happening on the ground, which also limited our understanding and ability to make recommendations.

\section{Conclusions}

It is noteworthy that our approach to risk modeling to targeted surveillance in areas hitherto not known to be VL endemic proved to be useful. We showed the presence 
Table 4 Risk factors associated with asymptomatic visceral leishmaniasis as measured by the leishmanin skin test, Benishangul-Gumuz, western Ethiopia, 2018-2020

\begin{tabular}{|c|c|c|c|c|}
\hline Risk factors & COR (95\% Cl) & $P$ value & AOR $(95 \% \mathrm{Cl})$ & $P$ value \\
\hline \multicolumn{5}{|l|}{ Own dog } \\
\hline Yes & $3.37(2.08,5.46)$ & 0.000 & $2.6(1.54,4.40)$ & 0.000 \\
\hline No & 1 (Ref.) & - & 1 (Ref.) & - \\
\hline \multicolumn{5}{|l|}{ Sex } \\
\hline Male & 1 (Ref.) & - & 1 (Ref.) & - \\
\hline Female & $0.43(0.23,0.79)$ & 0.006 & $0.38(0.19,0.72)$ & 0.003 \\
\hline \multicolumn{5}{|l|}{ Age (years) } \\
\hline$<5$ & 1 (Ref.) & - & 1 (Ref.) & - \\
\hline $5-12$ & $0.22(0.08,0.61)$ & 0.004 & $0.40(0.13,1.24)$ & 0.112 \\
\hline $13-18$ & $0.65(0.36,1.18)$ & 0.156 & $1.23(0.59,2.58)$ & 0.586 \\
\hline$>18$ & - & - & - & - \\
\hline \multicolumn{5}{|l|}{ Woreda } \\
\hline Pawi & 1 (Ref.) & - & 1 (Ref.) & - \\
\hline Guba & $6.83(2.79,16.73)$ & 0.000 & $4.74(1.83,12.31)$ & 0.001 \\
\hline Dangur & $1.36(0.45,4.11)$ & 0.589 & $0.91(0.29,2.86)$ & 0.874 \\
\hline Bambasi & 1 & - & - & - \\
\hline Kurmuk & $5.87(2.37,14.55)$ & 0.000 & $5.85(2.27,15.09)$ & 0.000 \\
\hline Sherkole & 1 & - & - & - \\
\hline \multicolumn{5}{|l|}{ Occupation } \\
\hline Farmer & 1 (Ref.) & - & 1 (Ref.) & - \\
\hline Trader & $0.69(0.08,5.86)$ & 0.737 & $0.28(0.03,2.67)$ & 0.270 \\
\hline Civil servant & $0.14(0.02,1.06)$ & 0.056 & $0.09(0.01,0.72)$ & 0.023 \\
\hline Laborer & 1 & - & - & - \\
\hline Driver & - & - & - & - \\
\hline Students & $0.35(0.19,0.64)$ & 0.001 & $0.52(0.24,1.13)$ & 0.102 \\
\hline
\end{tabular}

of active VL transmission in a key developmental corridor, Benishangul-Gumuz. We recommend the that the regional health bureau and responsible stakeholders be vigilant and plan early containment measures to avoid possible public health and economic consequences due to $\mathrm{VL}$.

\section{Acknowledgements}

The cooperation of the health system from the region to the health post level was crucial. Dr. Solomon Mekuriaw, S/r seniya Asfir and Tiruwork Fanta are acknowledged for their support in different aspects.

\section{Authors' contributions}

Conceptualization: SB, GM, AM, NM, EG. Field and laboratory work: SB, DD, SW, GS. Data analysis and writing up: SB, EA, AK, GM, EG. Critical review: AK, AM, NM, GM, EG. All authors read and approved the final manuscript.

\section{Funding}

This study was funded by the WHO-Ethiopia country office. Armauer Hansen Research Institute (Norad and Sida core support) and Addis Ababa University partially supported the work.

\section{Availability of data and materials}

The data supporting the conclusions of this article are included within the article and anonymized data could be shared upon request to the corresponding author as per data sharing policy of the Armauer Hansen Research Institute.

\section{Ethics approval and consent to participate}

This research was approved by the AHRI/ALERT ethics committee (AH01275/0012/18, 19-12-18). Specimen collection was done with the informed consent of the household head for dogs. Informed consent of the participant, parent/or guardian for minors and verbal assent for 11 to 18 year olds in addition to the parental/legal guardian was sought for humans.

\section{Consent for publication \\ Not applicable.}

\section{Competing interests}

Dr. Nigus Manaye is the employee of the funding institute.

\section{Author details}

${ }_{1}^{1}$ Armauer Hansen Research Institute, Neglected Tropical Disease and Malaria Research Directorate, Addis Ababa, Ethiopia. ${ }^{2}$ Department of Veterinary Science, Assosa University College of Agriculture and Natural Resource, Assosa, Ethiopia. ${ }^{3}$ Department of Veterinary Microbiology, Immunology and Public Health, Addis Ababa University College of Veterinary Medicine and Agriculture Debre-Zeyit, Ethiopia. ${ }^{4}$ World Health Organization-Regional Office for Africa, Brazzaville, Congo. ${ }^{5}$ World Health Organization Ethiopia Country Office, Addis Ababa, Ethiopia.

Received: 11 August 2020 Accepted: 11 December 2020

Published online: 11 January 2021

\section{Reference}

1. Jambulingam P, Pradeep Kumar N, Nandakumar S, Paily KP, Srinivasan R. Domestic dogs as reservoir hosts for Leishmania donovani in the southernmost Western Ghats in India. Acta Trop. 2017;171:64-7.

2. Hassan MM, Osman OF, El-Raba'a FM, Schallig HD, Elnaiem DE. Role of the domestic dog as a reservoir host of Leishmania donovani in eastern Sudan. Parasit Vectors. 2009;2(1):26.

3. Dereure J, El-Safi SH, Bucheton B, Boni M, Kheir MM, Davoust B, Pratlong F, Feugier E, Lambert M, Dessein A, et al. Visceral leishmaniasis in eastern Sudan: parasite identification in humans and dogs; host-parasite relationships. Microbes Infect. 2003;5(12):1103-8.

4. Bsrat A, Berhe M, Gadissa E, Taddele H, Tekle Y, Hagos Y, Abera A, Alemayhu T, Gugsa G, et al. Serological investigation of visceral Leishmania infection in human and its associated risk factors in Welkait District, Western Tigray, Ethiopia. Parasite Epidemiol Control. 2018;3(1):13-20.

5. Bashaye S, Nombela N, Argaw D, Mulugeta A, Herrero M, Nieto J, Chicharro C, Canavate C, Aparicio P, Velez ID, et al. Risk factors for visceral leishmaniasis in a new epidemic site in Amhara Region, Ethiopia. Am J Trop Med Hygiene. 2009;81(1):34-9.

6. Kalayou S, Tadelle H, Bsrat A, Abebe N, Haileselassie M, Schallig HD. Serological evidence of Leishmania donovani infection in apparently healthy dogs using direct agglutination test (DAT) and rk39 dipstick tests in Kafta Humera, north-west Ethiopia. Transbound Emerging Dis. 2011;58(3):255-62.

7. Gebresilassie A, Abbasi I, Aklilu E, Yared S, Kirstein OD, Moncaz A, Tekie $\mathrm{H}$, Balkew M, Warburg A, Hailu A, et al. Host-feeding preference of Phlebotomus orientalis (Diptera: Psychodidae) in an endemic focus of visceral leishmaniasis in northern Ethiopia. Parasit Vectors. 2015;8:270.

8. Yared S, Gebresilassie A, Abbasi I, Aklilu E, Kirstein OD, Balkew M, Brown AS, Clouse RM, Warburg A, Hailu A, et al. A molecular analysis of sand fly blood meals in a visceral leishmaniasis endemic region of northwestern Ethiopia reveals a complex host-vector system. Heliyon. 2019;5(7):e02132.

9. Alvar J, Bashaye S, Argaw D, Cruz I, Aparicio P, Kassa A, Orfanos G, Parreno F, Babaniyi O, Gudeta N, et al. Kala-azar outbreak in Libo Kemkem, Ethiopia: epidemiologic and parasitologic assessment. Am J Trop Med Hygiene. 2007;77(2):275-82.

10. Gebremichael Tedla D, Bariagabr FH, Abreha HH. Incidence and trends of leishmaniasis and its risk factors in humera, western tigray. J Parasitol Res. 2018;2018:8463097

11. Gadisa E, Tsegaw T, Abera A, Elnaiem DE, den Boer M, Aseffa A, Jorge A. Eco-epidemiology of visceral leishmaniasis in Ethiopia. Parasites Vectors. 2015;8:381. 
12. Custodio E, Gadisa E, Sordo L, Cruz I, Moreno J, Nieto J, Chicharro C, Aseffa A, Abraham Z, Hailu T. Factors associated with Leishmania asymptomatic infection: results from a cross-sectional survey in highland northern Ethiopia. PLoS Neglected Trop Dis. 2012;6(9):e1813.

13. FMoH: Guideline for diagnosis, treatment and prevention of leishmaniasis in Ethiopia. Edited by Unit N, second edn. Addis Ababa: Ethiopian Federal Ministry of Health; 2013

14. Tsegaw T, Gadisa E, Seid A, Abera A, Teshome A, Mulugeta A, Herrero $M$, Argaw D, Jorge A, Aseffa A. Identification of environmental parameters and risk mapping of visceral leishmaniasis in Ethiopia by using geographical information systems and a statistical approach. Geospatial Health. 2013;7(2):299-308.

15. Abera A, Tasew G, Tsegaw T, Kejella A, Mulugeta A, Worku D, Aseffa A, Gadisa E. Visceral leishmaniasis in Benishangul-Gumuz Regional State, Western Ethiopia: reemerging or emerging? Am J Trop Med Hygiene. 2016;95(1):104-8.

16. Abera A, Tasew G, Degu A, Almneh M, Mulugeta A, Aseffa A, Gadisa E. Visceral leishmaniasis from an area previously not known to be endemic; dangur, benshangul-gumuz, regional state, northwest ethiopia: a case report. Ethiop Med J. 2016;54(1):33-6.

17. Gadisa E, Custodio E, Cañavate C, Sordo L, Abebe Z, Nieto J, Chicharro C, Aseffa A, Yamuah L, Engers H. Usefulness of the
rK39-immunochromatographic test, direct agglutination test, and leishmanin skin test for detecting asymptomatic Leishmania infection in children in a new visceral leishmaniasis focus in Amhara State, Ethiopia. Am J Trop Med Hygiene. 2012;86(5):792-8.

18. Hailu A, Gramiccia M, Kager PA. Visceral leishmaniasis in Aba-Roba, southwestern Ethiopia: prevalence and incidence of active and subclinical infections. Ann Trop Med Parasitol. 2009;103(8):659-70.

19. Tadese D, Hailu A, Bekele F, Belay S. An epidemiological study of visceral leishmaniasis in North East Ethiopia using serological and leishmanin skin tests. PLoS ONE. 2019;14(12):e0225083.

20. Ali A. Leishmaniases survey in the Awash Valley: leishmanin skin test profile in the Upper Awash and surrounding areas. Ethiop Med J. 1997;35(4):225-33.

21. Alebie G, Worku A, Yohannes S, Urga B, Hailu A, Tadesse D. Epidemiology of visceral leishmaniasis in Shebelle Zone of Somali Region, eastern Ethiopia. Parasites Vectors. 2019;12(1):209.

\section{Publisher's Note}

Springer Nature remains neutral with regard to jurisdictional claims in published maps and institutional affiliations.
Ready to submit your research? Choose BMC and benefit from:

- fast, convenient online submission

- thorough peer review by experienced researchers in your field

- rapid publication on acceptance

- support for research data, including large and complex data types

- gold Open Access which fosters wider collaboration and increased citations

- maximum visibility for your research: over 100M website views per year

At BMC, research is always in progress.

Learn more biomedcentral.com/submissions 